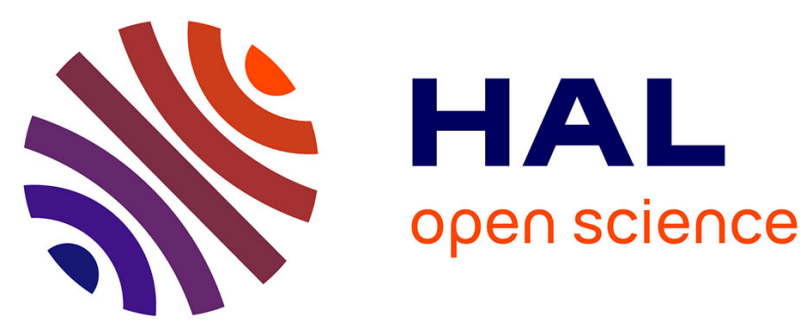

\title{
Serum interferon- $\alpha$ levels and IFN type I-stimulated genes score perform equally to assess systemic lupus erythematosus disease activity
}

François Chasset, Alexis Mathian, Karim Dorgham, Camillo Ribi, Marten Trendelenburg, Uyen Huynh-Do, Pascale Roux-Lombard, Delphine Sophie Courvoisier, Zahir Amoura, Guy Gorochov, et al.

\section{To cite this version:}

François Chasset, Alexis Mathian, Karim Dorgham, Camillo Ribi, Marten Trendelenburg, et al.. Serum interferon- $\alpha$ levels and IFN type I-stimulated genes score perform equally to assess systemic lupus erythematosus disease activity. Annals of the Rheumatic Diseases, In press, pp.annrheumdis2021-221835. 10.1136/annrheumdis-2021-221835 . hal-03553438

\section{HAL Id: hal-03553438 https://hal.science/hal-03553438}

Submitted on 2 Feb 2022

HAL is a multi-disciplinary open access archive for the deposit and dissemination of scientific research documents, whether they are published or not. The documents may come from teaching and research institutions in France or abroad, or from public or private research centers.
L'archive ouverte pluridisciplinaire HAL, est destinée au dépôt et à la diffusion de documents scientifiques de niveau recherche, publiés ou non, émanant des établissements d'enseignement et de recherche français ou étrangers, des laboratoires publics ou privés. 


\title{
Serum interferon- $\alpha$ levels and IFN type l-stimulated genes score perform equally to assess systemic lupus erythematosus disease activity
}

François Chasset ,1,2,3 Alexis Mathian,1,4 Karim Dorgham,1 Camillo Ribi,5 Marten Trendelenburg ,6,7 Uyen Huynh-Do,8 Pascale Roux-Lombard,9 Delphine Sophie Courvoisier,10 Zahir Amoura,1,4 Guy Gorochov,1 Carlo Chizzolini 3

\author{
${ }^{1}$ Sorbonne Université, Inserm, Centre d'Immunologie et des Maladies Infectieuses (CIMI-Paris), Assistance \\ Publique-Hôpitaux de Paris, Groupement Hospitalier Pitié-Salpêtrière, Département d'Immunologie, \\ Paris, France \\ ${ }^{2}$ Sorbonne Université, Faculté de Médecine, Assistance Publique-Hôpitaux de Paris, Service de \\ Dermatologie et Allergologie, Hôpital Tenon, F-75020 Paris, France \\ ${ }^{3}$ Department of Pathology and Immunology, Centre Médical Universitaire, School of Medicine, Geneva, \\ Switzerland \\ ${ }^{4}$ Sorbonne université, Faculté de médecine, Assistance Publique-Hôpitaux de Paris, Groupement \\ Hospitalier Pitié-Salpêtrière, French National Referral Center for Systemic Lupus Erythematosus, \\ Antiphospholipid Antibody Syndrome and Other Autoimmune Disorders, Service de Médecine Interne 2, \\ Institut E3M, Paris, France \\ ${ }^{5}$ Division of Immunology and Allergy, University Hospital Center of Lausanne, Lausanne, Switzerland \\ ${ }^{6}$ Clinical Immunology, Department of Biomedicine, University Hospital Basel, Basel, \\ Switzerland \\ ${ }^{7}$ Division of Internal Medicine, University Hospital Basel, Basel, Switzerland \\ ${ }^{8}$ Division of Nephrology and Hypertension, University Hospital Bern, Bern, \\ Switzerland \\ ${ }^{9}$ Laboratory of Clinical Immunology and Allergy, University Hospital and School of Medicine, Geneva, \\ Switzerland \\ ${ }^{10}$ Division of Clinical Epidemiology, University of Geneva, Geneva, Switzerland \\ Correspondence to Dr François Chasset, Service de Dermatologie et Allergologie, Hôpital Tenon, \\ Assistance Publique - Hôpitaux de Paris, 75020 Paris, Île-de-France, France; francois.chasset@gmail.com
}

Dysregulation of type I interferon (IFN-I) signalling plays a major role in systemic lupus erythematosus (SLE) pathogenesis.1 Selected IFN-stimulated genes (ISGs) are used to generate scores and were shown to be associated with specific clinical phenotypes, SLE activity, risk of flares and response to treatment targeting IFN-I.2 3 IFN-I gene scores are highly heterogeneous in the number of included ISGs and are not standardised for the use in routine clinical practice. Serum IFN- $\alpha$ levels detected by digital ELISA by single molecule array were shown to be a promising biomarker of SLE activity4 and predictor of flares among patients with SLE in remission. 5 IFN- $\gamma$ may also play a role in SLE pathogenesis and it has been shown that several genes that are upregulated by IFN- $\alpha$ are upregulated also by IFN- $\gamma .6$ In the present study, we aimed at assessing whether IFN-I gene score in blood and IFN- $\alpha$ or IFN- $\gamma$ levels quantified by digital ELISA in serum performed similarly as biomarkers, mirroring the clinical activity of SLE. Moreover, we investigated by correlative evidence the contribution of IFN- $\alpha$ and IFN- $\gamma$ to the expression levels of different ISGs and of an IFN-I gene score.

Gene expression was assessed by mRNA profiling using the NanoString nCounter gene expression system (NanoString Technologies, Seattle, Washington). Serum IFN- $\alpha$ and IFN- $\gamma$ levels were quantified by digital ELISA technology (Quanterix Simoa, Lexington, Massachusetts, USA). Detailed methodology is available in online supplemental document S1. The clinical characteristics of the 133 patients with SLE included in the present study are reported in online supplemental table S1. Median age was 45.6 (range 19-78.8) years, 111 
(83\%) were women, 98 (74\%) were Caucasians and 75 patients (56\%) had an active disease using clinical Systemic Lupus Erythematosus Disease Activity Index (cSLEDAI), the contribution of low serum complement and elevated anti-dsDNA autoantibodies with a cut-off $>0$ to define active disease was excluded.4

Using the predefined cut-offs, 34 the prevalence of high IFN-I gene scores, elevated IFN- $\alpha$ and IFN- $\gamma$ serum levels were 44\% (58/133), 45\% (60/133) and 14\% (18/133), respectively (figure 1A). Serum IFN- $\alpha$ levels showed a highly positive correlation with the IFN-I gene scores (Spearman's correlation coefficient: $r h o=0.82$ ), as well as with the expression level of individual ISGs except for CXCL10 (figure 1B,C). In contrast, IFN- $\gamma$ levels showed a weak positive correlation with IFN-I gene scores (rho=0.32) (figure 1D) and IFN- $\alpha$ levels (rho=0.35), as well as with the expression level of individual ISG, except for CXCL10 which showed a stronger positive correlation ( $r h o=0.60$ ) in accordance with a preferential induction of CXCL10 by IFN- $\nu$ (figure 1C). Using Cohen's kappa coefficient, serum IFN- $\alpha$ levels showed substantial agreement to classify SLE with high or low IFN-I gene scores $\mathrm{k}=0.72$ ( $95 \% \mathrm{Cl}: 0.60$ to 0.84 ), whereas the agreement was low for IFN- $\gamma$ (figure 1B,D). The sensitivity, specificity, negative and positive predictive values of serum IFN- $\alpha$ levels to classify SLE with high or low IFN-I gene score were $86 \%, 87 \%, 89 \%$ and $83 \%$, respectively.

Moreover, elevated serum IFN- $\alpha$ levels and IFN-I gene scores were associated with active SLE, as defined by cSLEDAI $>0$ or SLEDAI $\geq 4$ (online supplemental figure $s 1-s 3$ ) and were both associated with active skin lesions, arthritis and positive anti-dsDNA Abs in multivariable analysis (online supplemental table s2). In contrast, IFN- $\gamma$ was neither associated with active SLE (online supplemental figure s1) nor with active SLE characteristics (online supplemental figure s2).

Finally, IFN-I gene score $A U C=0.63(95 \% \mathrm{Cl}$ : 0.53 to 0.72$)$ and serum IFN- $\alpha$ AUC $=0.63(95 \% \mathrm{Cl}$ : 0.53 to 0.72 ) performed similarly and significantly better than C3 levels AUC $=0.42(95 \% \mathrm{Cl}$ : 0.32 to 0.52 ) to discriminate inactive versus active SLE adjusted $p$ value $=0.03$ and 0.03 , respectively (online supplemental figure $s 3$ and table $s 3$ ).

In this study, for the first time, we show that IFN- $\alpha$ assessed by digital ELISA and IFN-I gene score perform equally for identifying the association of IFN-I with SLE disease activity and clinical manifestations. Remarkably, this was specific to IFN- $\alpha$, since no such association was observed with serum IFN- $\gamma$ levels. Of importance, we observed no association of IFN- $\gamma$ serum levels with active SLE clinical features and SLEDAI. This may suggest that IFN- $\gamma$ serum levels may not perform optimally as SLE biomarkers and may not support the choice of IFN- $\gamma$ as therapeutic target. However, further studies are needed to explore this issue. The limitations of our study are the cross-sectional design and the relatively low number of highly active patients with SLE, which reflects real-life practice in Switzerland.

IFN- $\alpha$ levels measured by digital ELISA could be easier to standardise than IFN-I gene scores to characterise IFN-I overexpression in clinical practice.

\section{REFERENCES}

1 Bennett L, Palucka AK, Arce E, et al. Interferon and granulopoiesis signatures in systemic lupus erythematosus blood. J Exp Med 2003;197:711-23.

2 Khamashta M, Merrill JT, Werth VP, et al. Sifalimumab, an anti-interferon- $\alpha$ monoclonal antibody, in moderate to severe systemic lupus erythematosus: a randomised, doubleblind, placebo-controlled study. Ann Rheum Dis 2016;75:1909-16.

3 Chasset $F$, Ribi C, Trendelenburg M, et al. Identification of highly active systemic lupus erythematosus by combined type I interferon and neutrophil gene scores vs classical 
serologic markers. Rheumatology 2020;59:3468-78.

4 Mathian A, Mouries-Martin S, Dorgham K, et al. Monitoring disease activity in systemic lupus erythematosus with single-molecule array digital enzyme-linked immunosorbent assay quantification of serum interferon- $\alpha$. Arthritis Rheumatol 2019;71:756-65.

5 Mathian A, Mouries-Martin S, Dorgham K, et al. Ultrasensitive serum interferon- $\alpha$ quantification during SLE remission identifies patients at risk for relapse. Ann Rheum Dis 2019;78:1669-76.

6 Hall JC, Casciola-Rosen L, Berger AE, et al. Precise probes of type II interferon activity define the origin of interferon signatures in target tissues in rheumatic diseases. Proc Natl Acad Sci U S A 2012;109:17609-14.
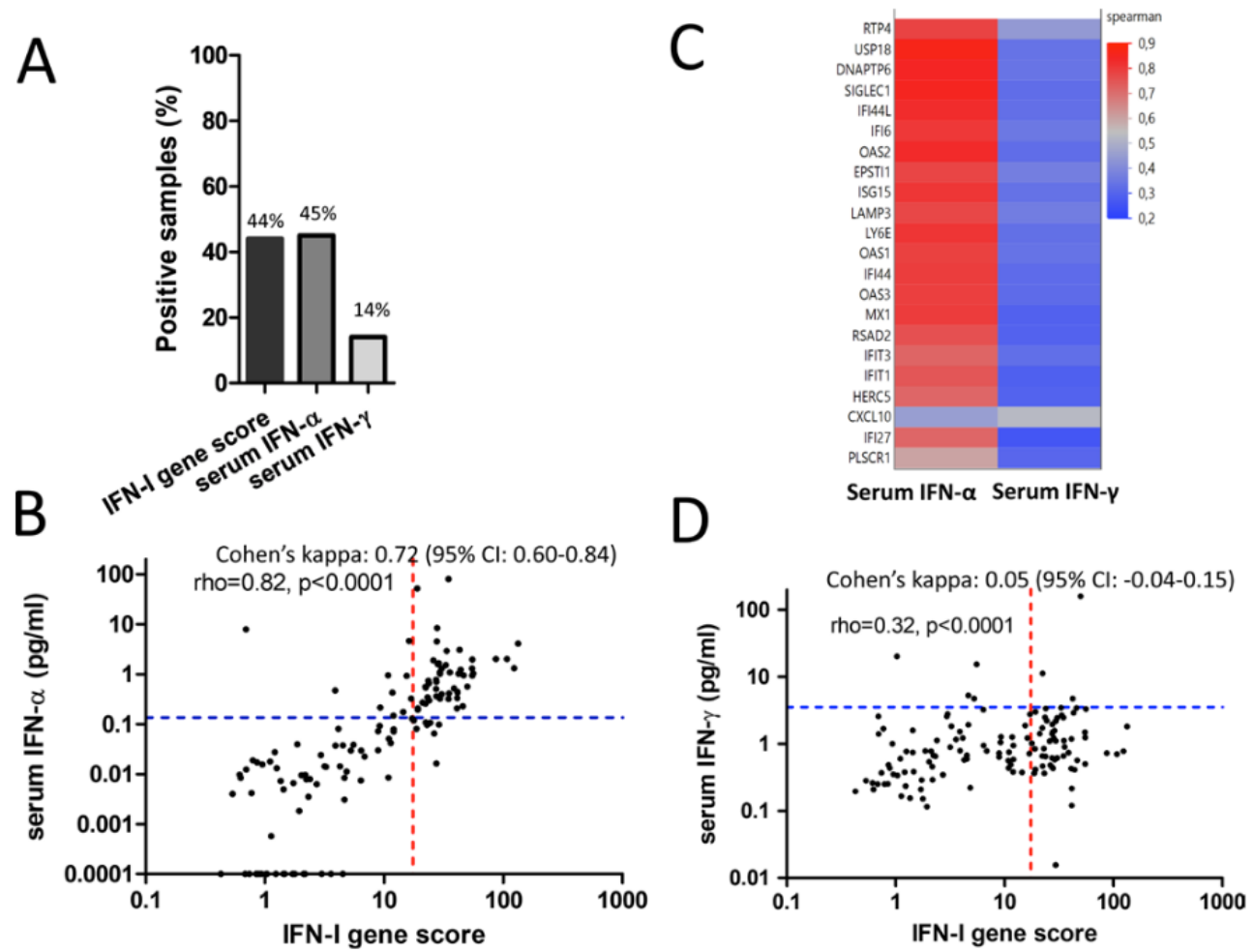

Figure 1

Prevalence, correlation and agreement between serum IFN- $\alpha$ and IFN-I gene score. (A) Prevalence of high serum IFN- $\alpha$, serum IFN- $\gamma$ and IFN-I gene score. A custom panel of 22 genes was developed and we calculated one IFN-I gene score (IFI27, IFI44, IFI44L, RSAD2)2 with a cut-off $\geq 17.5$ to define high score. 3 Cut-off for high serum IFN- $\alpha$ was $136 \mathrm{fg} / \mathrm{mL}$ (blue line) as previously defined, 4 cut-off for high IFN-gene score was 17.5 (red line) as previously defined3 and cut-off for high IFN- $\gamma$ was $2558 \mathrm{fg} / \mathrm{mL}$ based on 3 SD above the mean from $74 \mathrm{HC}$ to define elevated IFN- $\gamma$ levels. (B) Spearman correlation coefficient (rho) between IFN-I gene scores and serum IFN- $\alpha$ values and Cohen's kappa to assess agreement between IFN-I gene score and serum IFN- $\alpha$ to classify patients with SLE. (C) Correlation matrix diagram of individual IFN genes with serum IFN- $\alpha$ and serum IFN- $\gamma$ levels. Spearman correlation analysis (rho) was applied and values were condensed in a colour scale. (D) Spearman correlation ( $r s$ ) between IFN-I gene score and serum IFN- $\gamma$ and Cohen's kappa to assess agreement between IFN-I gene score and serum IFN- $\gamma$ to classify patients with systemic lupus erythematosus (SLE). IFN, interferon. 


\section{ONLINE SUPPLEMENT}

\section{PATIENTS AND METHODS}

\section{Study design, patients and healthy controls}

Biological samples were collected from 133 consecutive SLE patients included in the Swiss SLE Cohort Study (SSCS) between November 2017 and December 2018. Inclusion criteria were age $\geq 18$ years, diagnosis of SLE according to the updated American College of Rheumatology classification criteria [1] or the SLICC 2012 [2]. The cohort study was approved by the SwissEthics review board (PB_2017-01434) and all patients gave written informed consent.

Thirty-five age- and sex-matched healthy controls (HCs) were selected from the Geneva Blood donation bank following classical guidelines on assessing donor suitability for blood donation. In particular, fever or viral symptoms the week before blood sampling were exclusion criteria. HCs could not be matched based on ethnicity and ancestry.

\section{Patient and public involvement.}

No patients nor public were involved in the conception or realization of the present study.

\section{Data collection and definitions}

We collected demographic data, SLE clinical characteristics, the Safety of Estrogens in Lupus Erythematosus National Assessment-Systemic Lupus Erythematosus Disease Activity Index (SELENA-SLEDAI) [3]. The therapeutic regimen was recorded on the day of sample collection. Biological data collected were complete blood count, serum creatinine level, proteinuria, and complement C3 and C4 levels. Testing for anti-dsDNA (Q'Flash dsDNA Kit, Ruwag Life Science, Switzerland), anti- $U_{1} R N P$, anti-SSA, anti-C1q antibodies (ELISA, Ruwag Life Science, Switzerland) was performed according to manufacturer protocols in a central laboratory in Geneva (Switzerland). Medication with disease-modifying drugs was classified in four groups: 1) no treatment versus active treatment, 2) antimalarial (AM) therapy only, 3) systemic glucocorticoids (GC) and 4) immunosuppressant agents (IS). Active clinical features were based on SELENA-SLEDAI and active skin disease included at least one active SELENA- 
SLEDAI features among active lupus rash, mucosal ulcers and alopecia. Patients were classified in 2 groups active and inactive SLE according to a modified definition of active SLEDAI, named clinical SLEDAI, that excluded the contribution of low serum complement and elevated dsDNA autoantibodies with a cut-off $>0$ to define active disease.

\section{mRNA collection extraction and quality}

Whole blood was collected in Tempus tubes (Thermo Fisher Scientific, Waltham, USA), and stored at $-80^{\circ} \mathrm{C}$ until mRNA purification. Serum samples were collected concomitantly. Total RNA was extracted by using MagMA for the Stabilized Blood Tubes RNA Isolation Kit (Thermo Fisher Scientific) and RNA quality was assessed post-extraction in a subset of samples by bioanalyzer RNA chip (Agilent Technologies). RNA quality assessed by RNA Integrity Number (RIN) was good in representative samples, with values $>8$.

\section{Quantitative assessment of mRNA levels and gene normalization}

Gene expression was assessed by mRNA expression profiling by using a NanoString nCounter gene expression system (NanoString Technologies, Seattle, WA) as previously described [4]. Briefly, $100 \mathrm{ng}$ total RNA was hybridized to the probes (a reporter probe and a capture probe) at $67^{\circ} \mathrm{C}$ for $16-21 \mathrm{~h}$ by using a thermocycler. Samples were then inserted into the nCounter Prep Station for removing excessive probes, purification and immobilization onto the internal surface of a sample cartridge for 2 to $3 \mathrm{~h}$. Finally, the sample cartridge was transferred to the nCounter Digital Analyzer, where color codes were counted and tabulated for each target molecule. Background correction involved subtracting from the raw counts the mean +2 SD of counts obtained with negative controls (alien probes lacking spiked transcript for background calculation). Values $<1$ were fixed to 1 to avoid negative values after log transformation. Positive controls (alien sequences of RNA spiked at various concentrations to assess the overall assay performance) were used as quality assessment: the ratio between the highest and the lowest positive controls average among samples was <3. IFN-I, PMN and PB gene counts were normalized to the geometric mean of 7 housekeeping gene counts selected as the most stable by using the geNorm algorithm [5].

\section{Gene selection and computation of the IFN-I gene scores}

A literature review was performed to identify genes previously used to assess IFN-I signature as part of modules of genes [6] or as quantitative scores[7]. A custom panel of 23 genes was 
then developed allowing the computation of six IFN-I gene scores [7-12] as well as CXCL10 which was used in the Module M1.2 of Banchereau et al[6]. The detailed gene list used to generate each score, is the following IFI27, IFI6, RSAD2, IFI44, IFI44L, USP18, LY6E, OAS1, SIGLEC1, ISG15, IFIT1, OAS3, HERC5, MX1, LAMP3, EPSTI1, IFIT3, OAS2, RTP4, PLSCR1, DNAPTP6, TYK1, CXCL10

Moreover, our gene selection allowed the computation of the following IFN-I gene scores:

- Yao Y 2009 [7]: IFI27, IFI6, RSAD2, IFI44, IFI44L, USP18, LY6E, OAS1, SIGLEC1, ISG15, IFIT1, OAS3, HERC5, MX1, LAMP3, EPSTI1, IFIT3, OAS2, RTP4, PLSCR1, DNAPTP6

-Petri M 2009 [11]: IFI27, OAS3, IFI44

- McBride 2012 [8]: IFI27, IFI44, IFIT1, MX1, OAS1, OAS2, OAS3

- Rice 2013 [12]: IFI27, IFI44L, IFIT1, ISG15, RSAD2, SIGLEC1

- Morimoto 2015 [9]: EPSTI1, HERC5, TYK1

- Khamashta 2016 [10]: IFI27, IFI44, IFI44L, RSAD2

- Banchereau 2016 [6] (Module M1.2) (gene included are highlighted in bold): BATF2, BIRC4BP, CXCL10, DNAPTP6, EPSTI1, FLJ20035, ISG15, HERC5, HES4, IFI44, IFI44L, IFIT1, IFIT3, IFITM3, LAMP3, LY6E, MX1, OAS1, OAS2, OAS3, OASL, OTOF, RSAD2, RTP4, SERPING1, TRIM6

The computation of the score was performed as previously described [7,12]. Briefly, for each individual, the relative expression of each gene was computed by dividing its normalized value by the median of the normalized HC expression. Then IFN-I gene scores were calculated as the median of the relative expression of all genes contributing to the score. The mean plus 2 SD of HC values was used as a threshold to define high scores. Unless otherwise stated, the IFN-I gene score refers to the score of Khamastha et al. (10) with a cut-off of high score of $17.5 \mathrm{UI}$ as previously described[13]. In individual gene expression analysis, TYK1 was excluded because it was not expressed (count of 0 ) in most patients.

\section{Single-molecule array (Simoa) IFN- $\alpha$ and IFN- $\gamma$ digital ELISA}


The Simoa ${ }^{\mathrm{TM}}$ (single molecule array) HD-1 analyzer (Quanterix, Lexington, MA, USA) was used for ultrasensitive immunodetection (digital ELISA)[14] of IFN- $\alpha$ and IFN- $\gamma$, using singleplex bead-based assays and procedures obtained from Quanterix Corporation.

According to the manufacturer's instructions, the working dilutions were 1:2 for all sera. At low cytokine concentration, the percentage of bead-containing wells in the array that have a positive signal is proportional to the amount of cytokine present in the sample (digital measurement). At higher concentration, when most of the bead-containing wells have one or more labeled-cytokine molecules, the total fluorescence signal is proportional to the amount of cytokine present in the sample (analog measurement). Calibrators were run in duplicate and fit with a four-parameter logistic (4PL) regression, with 1/y2 weighting. Cytokine concentrations in serum samples were interpolated from the standard curves. We used a serum-IFN- $\alpha$ level threshold value of $136 \mathrm{fg} / \mathrm{mL}$ to define high IFN- $\alpha$ levels based on 3 SD above the mean value from $68 \mathrm{HC}$ as previously described[15] and an IFN- $\gamma$ threshold of $2558 \mathrm{fg} / \mathrm{mL}$ based on 3 SD above the mean value from $74 \mathrm{HC}$ to define elevated IFN- $\gamma$ levels.

\section{Statistical analysis}

Data are presented as median (interquartile (IQR) range) or counts (percentage). Chi-square test and Fisher's exact test were used to compare categorical variables; Mann-Whitney test was used to compare non-paired variables, and Spearman correlation analysis (rho) was used for correlations. Agreement for classifying SLE as having high IFN levels between IFN-I gene scores and IFN- $\alpha$ and IFN- $\gamma$ serum levels measured by SIMOA was assessed using Kappa coefficient, with values defined as follows: $0<\mathrm{K}<0.2$ slight; $0.2 \leq \mathrm{K}<0.4$ fair agreement, $0.4 \leq \mathrm{K}$ $<0.6$ moderate $0.60 \leq \mathrm{K}<0.80$ substantial agreement and $\mathrm{K} \geq 0.80$ almost perfect agreement[16]. In order to assess features associated with high IFN-I gene score and IFN- $\alpha$ or IFN- $\gamma$ serum levels, parameters with $p<0.2$ on univariable analysis were entered in multivariable logistic models. A 2 -tailed $p<0.05$ was considered statistically significant. The areas under (AUCs) the receiver operating characteristics (ROC) curves to differentiate active vs inactive SLE according to IFN- $\alpha$ and IFN- $\gamma$ serum levels, IFN-I gene score, C3 levels and anti-dsDNA titers were compared[17]. compared Analyses were performed with JMP v15 (SAS Institute Inc, Cary, NC). 


\section{References:}

1 Hochberg MC. Updating the American College of Rheumatology revised criteria for the classification of systemic lupus erythematosus. Arthritis Rheum 1997;40:1725. doi:10.1002/1529-0131(199709)40:9\&lt;1725::AID-ART29\&gt;3.0.CO;2-Y

2 Petri M, Orbai A-M, Alarcón GS, et al. Derivation and validation of the Systemic Lupus International Collaborating Clinics classification criteria for systemic lupus erythematosus. Arthritis Rheum 2012;64:2677-86. doi:10.1002/art.34473

3 Petri M, Kim MY, Kalunian KC, et al. Combined oral contraceptives in women with systemic lupus erythematosus. N Engl J Med 2005;353:2550-8. doi:10.1056/NEJMoa051135

4 Pescarmona R, Belot A, Villard M, et al. Comparison of RT-qPCR and Nanostring in the measurement of blood interferon response for the diagnosis of type I interferonopathies. Cytokine 2019;113:446-52. doi:10.1016/j.cyto.2018.10.023

5 Vandesompele J, De Preter K, Pattyn F, et al. Accurate normalization of real-time quantitative RT-PCR data by geometric averaging of multiple internal control genes. Genome Biol 2002;3:RESEARCH0034. doi:10.1186/gb-2002-3-7-research0034

6 Banchereau R, Hong S, Cantarel B, et al. Personalized Immunomonitoring Uncovers Molecular Networks that Stratify Lupus Patients. Cell 2016;165:551-65. doi:10.1016/j.cell.2016.03.008

7 Yao Y, Richman L, Higgs BW, et al. Neutralization of interferon-alpha/beta-inducible genes and downstream effect in a phase I trial of an anti-interferon-alpha monoclonal antibody in systemic lupus erythematosus. Arthritis Rheum 2009;60:1785-96. doi:10.1002/art.24557

8 McBride JM, Jiang J, Abbas AR, et al. Safety and pharmacodynamics of rontalizumab in patients with systemic lupus erythematosus: results of a phase I, placebo-controlled, double-blind, dose-escalation study. Arthritis Rheum 2012;64:3666-76. doi:10.1002/art.34632

9 Kennedy WP, Maciuca R, Wolslegel K, et al. Association of the interferon signature metric with serological disease manifestations but not global activity scores in multiple cohorts of patients with SLE. Lupus Sci Med 2015;2:e000080. doi:10.1136/lupus-2014000080

10 Khamashta M, Merrill JT, Werth VP, et al. Sifalimumab, an anti-interferon- $\alpha$ monoclonal antibody, in moderate to severe systemic lupus erythematosus: a randomised, doubleblind, placebo-controlled study. Ann Rheum Dis Published Online First: 23 March 2016. doi:10.1136/annrheumdis-2015-208562

11 Petri $M$, Singh $S$, Tesfasyone $H$, et al. Longitudinal expression of type I interferon responsive genes in systemic lupus erythematosus. Lupus 2009;18:980-9. doi:10.1177/0961203309105529 
12 Rice GI, Forte GMA, Szynkiewicz M, et al. Assessment of interferon-related biomarkers in Aicardi-Goutières syndrome associated with mutations in TREX1, RNASEH2A, RNASEH2B, RNASEH2C, SAMHD1, and ADAR: a case-control study. Lancet Neurol 2013;12:1159-69. doi:10.1016/S1474-4422(13)70258-8

13 Chasset F, Ribi C, Trendelenburg M, et al. Identification of highly active systemic lupus erythematosus by combined type I interferon and neutrophil gene scores vs classical serologic markers. Rheumatol Oxf Engl 2020;59:3468-78.

doi:10.1093/rheumatology/keaa167

14 Rissin DM, Kan CW, Campbell TG, et al. Single-molecule enzyme-linked immunosorbent assay detects serum proteins at subfemtomolar concentrations. Nat Biotechnol 2010;28:595-9. doi:10.1038/nbt.1641

15 Mathian A, Mouries-Martin S, Dorgham K, et al. Monitoring disease activity in systemic lupus erythematosus with single-molecule array digital ELISA quantification of serum interferon- $\alpha$. Arthritis Rheumatol Hoboken NJ Published Online First: 3 December 2018. doi:10.1002/art.40792

16 Landis JR, Koch GG. The measurement of observer agreement for categorical data. Biometrics 1977;33:159-74.

17 Goksuluk D, Korkmaz S, Zararsiz G, Karaağaoğlu AE (2016). easyROC: An Interactive Webtool for ROC Curve Analysis Using R Language Environment. The R Journal, 8(2):213-230. 


\section{RESULTS}

Supplementary table $\mathbf{~} 1$. Baseline characteristics and active features at the time of sampling in SLE patients ( $n=133)$

\begin{tabular}{|c|c|}
\hline Features & \\
\hline Female & $111(83)$ \\
\hline Age, median (range), years & $45.6(19-78.8)$ \\
\hline \multicolumn{2}{|l|}{ Ethnicity } \\
\hline Caucasian & $98(74)$ \\
\hline African & $16(12)$ \\
\hline Asian & $12(9)$ \\
\hline Others & $7(5)$ \\
\hline \multicolumn{2}{|c|}{ Active manifestations at the time of study } \\
\hline Fever & $5(4)$ \\
\hline Arthritis & $26(20)$ \\
\hline Cutaneous & $28(21)$ \\
\hline Serositis & $6(5)$ \\
\hline Neurological disorder & $9(7)$ \\
\hline Leukopenia & $6(5)$ \\
\hline Thrombocytopenia & $8(6)$ \\
\hline Proteinuria $>0.5 \mathrm{~g} / 24 \mathrm{~h}$ & $6(5)$ \\
\hline \multicolumn{2}{|l|}{ Immunological features (presence) } \\
\hline ANA* & $125(94)$ \\
\hline Anti-dsDNA & $61(46)$ \\
\hline Anti-SSA & $55(41)$ \\
\hline Anti-Sm* & $34(26)$ \\
\hline Anti- $U_{1}$ RNP & $37(28)$ \\
\hline Anti-C1q & $34(26)$ \\
\hline $\mathrm{aPL} *$ & $53(40)$ \\
\hline Low complement & $28(21)$ \\
\hline C3 (g/l) median, range* & $0.90(0.39-1.8)$ \\
\hline C4 (g/l) median, range* & $0.16(0.01-0.45)$ \\
\hline \multicolumn{2}{|l|}{ Activity } \\
\hline Clinical SLEDAI >0 & $75(56)$ \\
\hline Clinical SLEDAI, median (range) & $2(0-42)$ \\
\hline
\end{tabular}


Current treatment

No treatment

Antimalarials

Systemic glucocorticoids

Immunosuppressant agents

64 (48)

$B$ cell targeted agents

9 (7)

* historical

data: Antinuclear autoantibodies (ANA), Sm and aPL (antiphospholipid), C3 and C4. Double stranded DNA (ds-DNA), $U_{1}$ ribonucleoprotein (U1RNP), anti-C1q were determined by Q'Flash or ELISA as described in the methods section in supplementary material. SLEDAI, Safety of Estrogens in Lupus Erythematosus National Assessment-Systemic Lupus Erythematosus Disease Activity Index (SELENA-SLEDAI). 


\section{Supplementary Table s2. Association of high IFN-I gene score and high serum IFN- $\alpha$ with active SLE features}

\begin{tabular}{|c|c|c|c|c|c|c|c|c|c|c|}
\hline Features N (\%) $\ddagger$ & $\begin{array}{l}\text { Low IFN-I } \\
\text { score } \\
(n=73)\end{array}$ & $\begin{array}{l}\text { High IFN-I } \\
\text { score } \\
(n=57)\end{array}$ & $\begin{array}{c}p \text {-value } \\
\text { uni }\end{array}$ & $\begin{array}{c}\text { p-value } \\
\text { multi }\end{array}$ & $\begin{array}{c}\text { OR [95 Cl\%] } \\
\text { multivariable }\end{array}$ & $\begin{array}{l}\text { Low serum } \\
\qquad \begin{array}{l}\text { IFN- } \alpha \\
(n=73)\end{array}\end{array}$ & $\begin{array}{l}\text { High serum } \\
\text { IFN- } \alpha \\
(n=57)\end{array}$ & $\begin{array}{c}p \text {-value } \\
\text { uni }\end{array}$ & $\begin{array}{c}\text { p-value } \\
\text { multi }\end{array}$ & $\begin{array}{c}\text { OR }[95 \% \mathrm{Cl}] \\
\text { multivariable }\end{array}$ \\
\hline SLE fever & $0(0)$ & $5(9)$ & $0.01^{*}$ & 0.99 & - & $1(1)$ & $4(7)$ & 0.16 & 0.53 & $2.25[0.18-28.7]$ \\
\hline Arthritis & $7(10)$ & $19(33)$ & $0.007^{*}$ & $0.007 *$ & 4.81 [1.53-15.09]* & $10(14)$ & $16(28)$ & $0.04 *$ & 0.10 & $2.34[0.83-6.56]$ \\
\hline Pooled active skin & $8(11)$ & $20(35)$ & $0.0009 *$ & $0.01^{*}$ & $4.12[1.32-12.84]^{*}$ & $9(12)$ & $19(33)$ & $0.004^{*}$ & $0.04^{*}$ & $2.71[1.01-7.31]^{*}$ \\
\hline Serositis & $2(3)$ & $4(7)$ & 0.40 & - & - & $2(3)$ & $4(7)$ & 0.40 & - & - \\
\hline Neurological disorders & $3(4)$ & $6(11)$ & 0.18 & 0.98 & - & $4(5)$ & $5(9)$ & 0.46 & - & - \\
\hline Leukopenia & $0(0)$ & $5(9)$ & $0.01 *$ & 0.99 & - & $0(0)$ & $5(9)$ & $0.01 *$ & 0.99 & - \\
\hline Thrombocytopenia & $5(7)$ & $3(6)$ & 1 & - & - & $5(7)$ & $3(6)$ & 1 & - & - \\
\hline Proteinuria $>0.5 \mathrm{~g} / 24 \mathrm{~h}$ & $3(4)$ & $3(6)$ & 1 & - & - & $2(3)$ & $4(7)$ & 0.40 & - & - \\
\hline Low complement & $13(18)$ & $15(27)$ & 0.23 & & & $13(18)$ & $15(27)$ & 0.23 & & \\
\hline Positive anti-dsDNA Abs & $29(39)$ & $32(55)$ & 0.06 & $0.03^{*}$ & $2.59[1.08-6.18]^{*}$ & $25(34)$ & $36(60)$ & $0.003 *$ & $0.004 *$ & $3.27[1.45-7.38]^{*}$ \\
\hline Current vs No treatment & $12(17)$ & $2(4)$ & $0.02 *$ & $0.02 *$ & $0.11[0.02-0.73]^{*}$ & $10(14)$ & $4(7)$ & 0.26 & - & - \\
\hline AM only & $17(24)$ & $15(26)$ & 0.72 & - & - & $19(26)$ & $13(23)$ & 0.64 & - & - \\
\hline GC use & $25(34)$ & $28(49)$ & 0.08 & 0.82 & $1.10[0.46-2.67]$ & $24(33)$ & $29(51)$ & $0.04^{*}$ & 0.11 & $1.94[0.86-7.38]$ \\
\hline IS use & $35(49)$ & $29(51)$ & 0.80 & - & - & $37(51)$ & $27(47)$ & 0.65 & - & - \\
\hline
\end{tabular}

Values are expressed as $\mathrm{n}(\%)$.

IFN-I score according to [10].

$\ddagger$ \% Among available data ( 3 patients had missing data regarding active features and treatment),

$\checkmark$ including active cutaneous lupus, mucosal ulcers and alopecia,

$* p<0.05$

Variables with $\mathrm{P}<0.2$ on univariable regression were entered in multivariable logistic models. Abs, antibodies; AM, antimalarials; GC, glucocorticoids; IS,

immunosuppressant agents; multi, multivariable; uni, univariable. 
Supplementary Table s3. Diagnostic performance of serum IFN- $\alpha$ and IFN-I gene score to predict clinical activity based on clinical SLEDAI> 0

\begin{tabular}{|l|l|l|l|l|}
\hline \multirow{2}{*}{ Features } & \multicolumn{2}{|c|}{ Serum IFN- $\alpha$} & \multicolumn{2}{c|}{ IFN-I gene score } \\
\cline { 2 - 5 } & \multicolumn{1}{|c|}{$\begin{array}{c}\text { Predefined cut-off } \\
136 \mathrm{fg} / \mathrm{mL}\end{array}$} & $\begin{array}{c}\text { Optimal cut-off } \\
319 \mathrm{fg} / \mathrm{ml}\end{array}$ & $\begin{array}{c}\text { Predefined cut-off } \\
17.5 \mathrm{UI}\end{array}$ & $\begin{array}{c}\text { Optimal cut-off } \\
24.4 \mathrm{UI}\end{array}$ \\
\hline Sensitivity & $56 \%$ & $52 \%$ & $53 \%$ & $47 \%$ \\
\hline Specificity & $67 \%$ & $81 \%$ & $69 \%$ & $86 \%$ \\
\hline PPV & $69 \%$ & $78 \%$ & $69 \%$ & $81 \%$ \\
\hline NPV & $54 \%$ & $57 \%$ & $53 \%$ & $56 \%$ \\
\hline
\end{tabular}

PPV: Positive predictive value; NPV: Negative Predictive Value, Optimal cut-off were determined by the Youden Index (the sum of sensitivity and specificity - 1). By using an optimal cutoff computed using the Youden Index, only the specificity and the positive predictive value increased substantially, for both IFN-I gene scores and serum IFN- $\alpha$ levels. 
Supplementary Figure s1. Association between IFN-I gene score, serum IFN- $\alpha$ and serum IFN- $\gamma$ with SLE activity. Active SLE was defined by clinical SLEDAI $>0$. Applied statistics were the Chi-square test in $\mathbf{A}, \mathbf{C}$ and $\mathbf{E}$, and the Mann-Whitney $\mathbf{U}$ test in $\mathbf{B}, \mathbf{D}$ and $\mathbf{F}$. Similar results were observed after the exclusion of patients with African descent
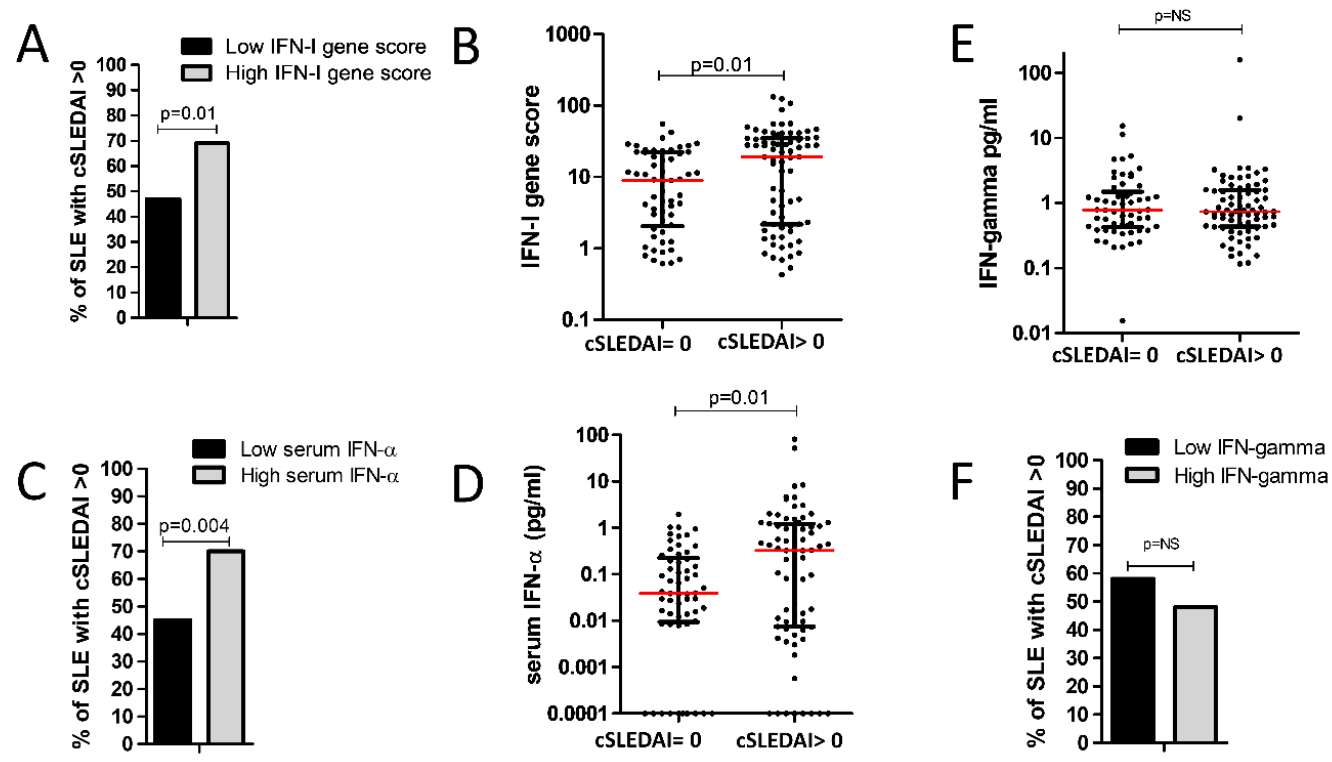

Supplementary Figure s2. Association between IFN-I gene score, serum IFN- $\alpha$ and serum IFN- $\boldsymbol{\gamma}$ with SLE activity. Active SLE was defined by SLEDAI $\geq 4$. Applied statistics were the Chisquare test in $\mathbf{A}, \mathbf{C}$ and $\mathbf{E}$, and the Mann-Whitney $\mathbf{U}$ test in $\mathbf{B}, \mathbf{D}$ and $\mathbf{F}$.
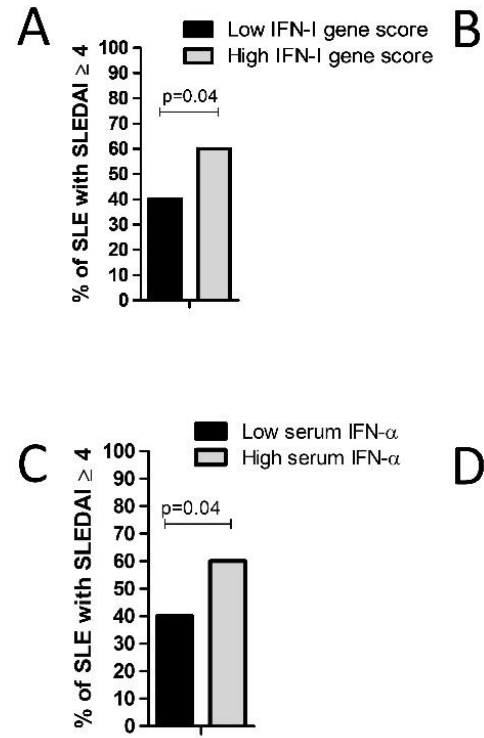
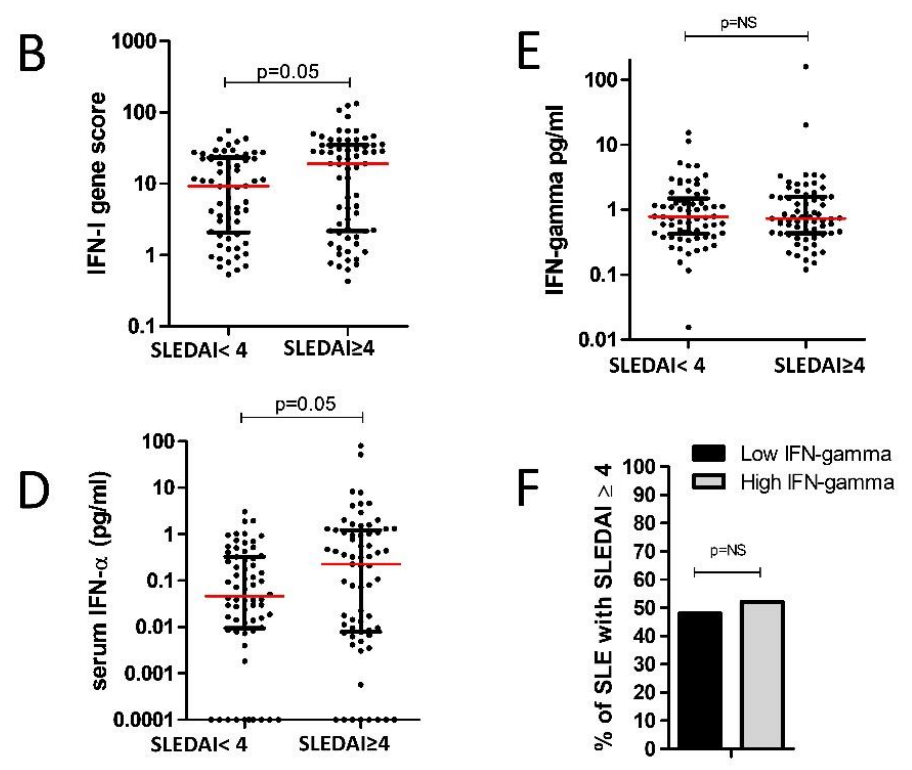


\section{Supplementary Figure s3. Comparison of clinical SLEDAI and SLEDAI among patients with} high or low IFN- $\alpha$, IFN- $\gamma$ levels or IFN-I score. A and B. High IFN-I score was defined by a score $>17.5 \mathrm{UI}$ as previously described[13]. C and D. A threshold value of $136 \mathrm{fg} / \mathrm{mL}$ was used to define high IFN- $\alpha$ levels based on $3 \mathrm{SD}$ above the mean value from $68 \mathrm{HC}$ as previously described [15] E and F. A threshold value of $2558 \mathrm{fg} / \mathrm{mL}$ was used to define high IFN- - based on 3 SD above the mean value from 74 HC. Applied statistics the Mann-Whitney $U$ test in all cases.

A

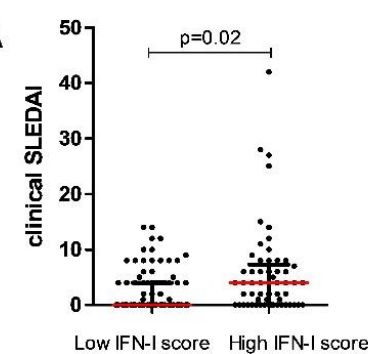

B

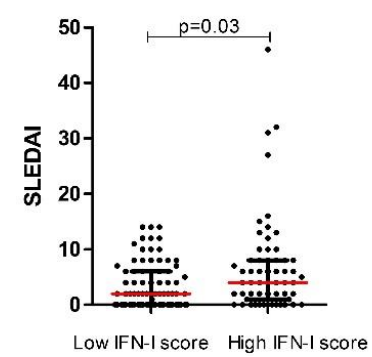

C

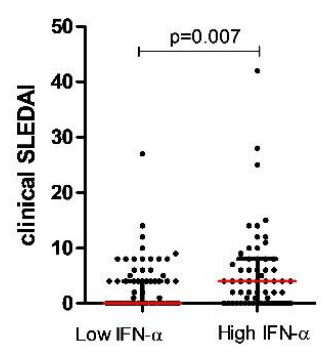

D

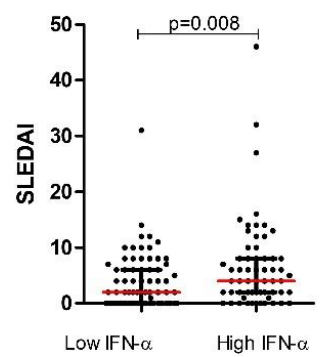

$E$

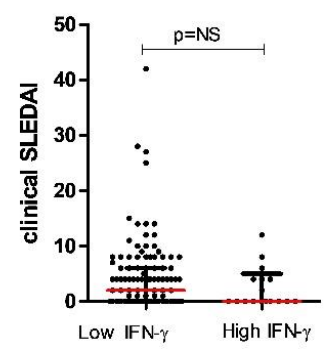

$\mathrm{F}$

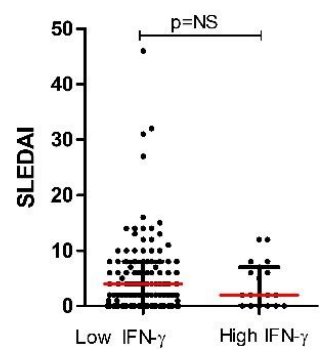


Supplementary Figure s4. Association between serum IFN- $\gamma$ levels with SLE activity and active phenotypes. Chi-square and Fisher's exact tests were used to compare categorical variables as appropriate. NS: Not significant

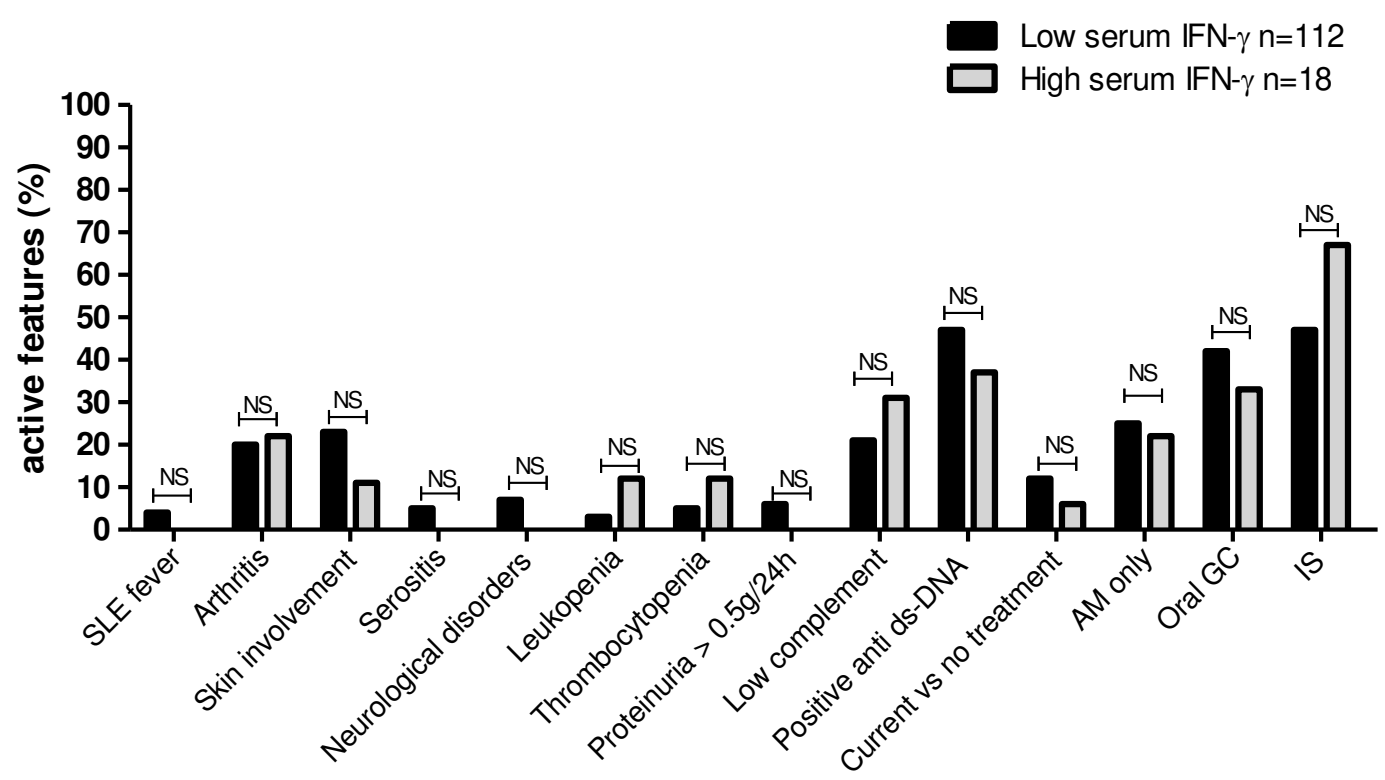




\section{Supplementary Figure s3. Receiver operative characteristic curve analysis of IFN-I gene} scores, serum IFN- $\alpha$ and IFN- $\psi$, C3 and anti-dsDNA levels discriminating active and inactive

SLE. SLE activity was defined according to clinical SLEDAI, inactive SLE (clinical SLEDAI=0) and active SLE (SLEDAI >0). AUC: area under the receiver operating characteristic curve.

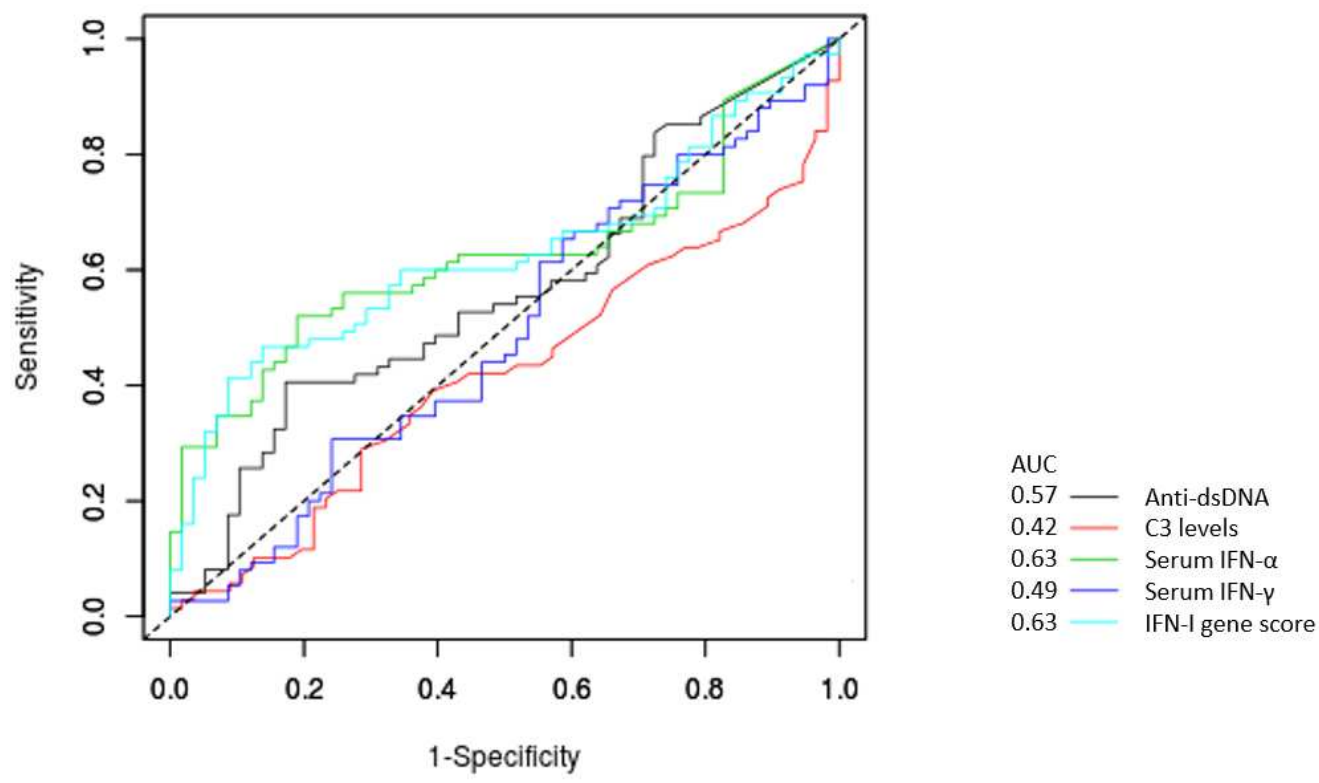

